\title{
Epidemiological Surveillance of Influenza Virus Matrix Gene in Pigs, in Lagos, Nigeria, 2015-2016
}

\author{
Anjorin A. Abdul-Azeez ${ }^{1,2,3}$, Salu B. Olumuyiwa ${ }^{2,3}$, Oyefolu O.B. Akeeb ${ }^{1}$, Oke O. Bamidele ${ }^{2}$, James B. \\ Ayorinde ${ }^{3,4}$, Orenolu R. Mercy ${ }^{3}$, Abdullah A. Maryam ${ }^{3}$, Anyanwu A. Roosevelt ${ }^{3}$, Oyibo A. Wellington ${ }^{2}$, \\ Omilabu A. Sunday ${ }^{2,3}$
}

\author{
${ }^{1}$ Department of Microbiology, Lagos State University, Ojo, Lagos, Nigeria. \\ ${ }^{2}$ Department of Medical Microbiology and Parasitology, College of Medicine, University of Lagos, Idi-Araba, Lagos, Nigeria. \\ ${ }^{3}$ Virology Research Laboratory, CRL, College of Medicine, University of Lagos, Idi-Araba, Lagos Nigeria. \\ ${ }^{4}$ Department of Biochemistry, College of Medicine, University of Lagos, Idi-Araba, Nigeria.
}

Received $12^{\text {th }}$ April 2017, Accepted $17^{\text {th }}$ July 2017

DOI: 10.2478/ast-2018-0001

*Corresponding author

A. A. Anjorin email: abdul-azeez.anjorin@lasu.edu.ng

Tel: +2348020956357

\begin{abstract}
The co-infection of different influenza A virus enable viral gene re-assortments especially in pigs that serve as mixing vessel with the possibility of emergence of novel subtypes. Such re-assortants pose serious public health threat, as epitomised by the emergence of pandemic influenza in 2009. In Nigeria, there is mixture of animal species and highly populated densities that can increase the risk of influenza virus endemicity, genetic reshuffling and emergence of future pandemic influenza viruses. Thus, this study was aimed at determining influenza virus disease burden in pigs. This study was a cross sectional molecular surveillance of influenza virus. A total of 194 pig nasal samples from reported cases and randomly sampled were collected from pig farms in Ojo and Ikorodu in Lagos State between October, 2015 and April, 2016. The samples were investigated for the presence of influenza virus matrix gene by Reverse Transcriptase Polymerase Chain Reaction and detected by gel electrophoresis. P-values were calculated using Chi-square and Fisher's exact tests. The result showed that $25(12.9 \%)$ samples were positive for influenza A virus, out of which, $20(80 \%)$ were samples from Ojo while $5(20 \%)$ were samples from Ikorodu. Epidemiological parameters for the sampled locations, methods either as reported case or randomised, and sex compared were significant at $95 \%$ confidence interval.This study determined influenza viral burden in pigs with a molecular prevalence of $12.9 \%$ to influenza A. It further confirmed the sub-clinical and clinical circulation of Influenza A virus in pigs in Ojo and Ikorodu in Lagos. Therefore, the detection of influenza A virus in commercial pigs in Nigeria accentuates the importance of continuous surveillance and monitoring of the virus in order to prevent the advent of virulent strains that may spread to Pig-handlers and the community at large.
\end{abstract}

Keywords: Influenza virus; Pigs; Molecular method; Influenza pandemic; Lagos 


\subsection{Introduction}

Swine influenza is a fast spreading respiratory or wheezing disease of pigs caused by Influenza A virus with common subtypes as H1N1, H1N2, H2N3, H3N1 and H3N2 (Sharma 2013), which are antigenically related to human Influenza viruses (IVs). It has been reported to circulate in pigs all year round with most outbreak occurrence in late fall and winter periods often at the onset of cold weather similar to outbreaks in humans (C.D.C., 2015). In the tropical region, infection may occur at any time. It is normally heralded by one or two cases before spreading round the herd, usually via aerosolisation, pig-to-pig close contact and by vehicle or fomite transmission (Torremorell, et al., 2012). Swine influenza virus cause low mortality but high morbidity in pigs (Yu et al., 2009). It survives in carrier pigs for up to 3 months and can be recovered from healthy animals between outbreaks (Dee, 2014).

Carrier pigs are usually responsible for the introduction of SIV into previously uninfected herds, geographical locations and countries. Infected swine herds, including those vaccinated against swine flu, may have sporadic disease, or may show only mild or no symptoms of infection (C.D.C., 2014). In humans, SIVs are sometimes referred to as variant influenza viruses. Interspecies gene reassortment and advent of novel viral strains could emerge from pigs because they express sialic acid receptor that can bind to both avian influenza virus ( $\mathrm{N}$-acetyl neuraminic acida2,3-galactose-NeuAc-a2,3Gal) and human influenza virus $(\mathrm{N}$ acetyl neuraminic acid-a2,6-galactose-NeuAc-a2,6Gal) (Imai \& Kawaoka, 2012; Imai et al., 2012; Rogers \& Paulson, 1983). An example is the influenza $\mathrm{A}(\mathrm{H} 1 \mathrm{~N} 1)$ pdm09 virus with combined gene segments from human, avian, and different SIVs, where pigs served as 'mixing vessels' (Garten et al., 2009; Smith et al., 2009).

The influenza $\mathrm{A}(\mathrm{H} 1 \mathrm{~N} 1)$ pdm09 infected humans, pigs, birds, dogs, cats, and others (Dee, 2014). Sporadic fatal influenza cases in pig farmers and other persons in close contact with pigs continued to be reported with more deaths recorded in immunocompromised people (Myers et al., 2007). One hundred (100) cases of human novel reassortant gene swine-origin $\mathrm{H} 3 \mathrm{~N} 2 \mathrm{v}$ IV with matrix gene segment of influenza $\mathrm{A}(\mathrm{H} 1 \mathrm{~N} 1)$ pdm09 origin have been circulating in the USA since July, 2011 and are being monitored for pandemic potential (C.D.C., 2012; Lindstrom et al., 2012). The highly populated densities and rearing of different animal species in farms seen in Nigeria, increases the risk on the endemicity of the virus in our environment, possibilities of genetic reshuffling and emergence of future pandemic influenza viruses.

Thus, this study was aimed at detecting influenza virus in pigs in Lagos, Nigeria.

\subsection{Materials and Methods}

\subsection{Study Design}

This study was a cross-sectional study on the molecular epidemiology surveillance of influenza virus using both reported and randomized sampling techniques in sick and healthy subjects respectively among pigs housed in pens of backyard and commercial farm settings. Subject of both sexes were considered for this study. Designed Questionnaires were administered for data collection.

\subsection{Sampling Location}

Lagos State has a land area of 356,861 hectares (h), including $75,755 \mathrm{~h}$ of wetlands (Bakare, 2016). It is divided into five divisions consisting of Badagry, Epe, Ikeja, Ikorodu, and Lagos Island with different farms spreading across the divisions where animals including pigs are reared and sold in mixed husbandry practice.

Samples for this study were collected from Ojo and Igbokuta in Badagry and Ikorodu divisions respectively. These sampling locations included farm settlements for private owners, government and commercial farming. Seven different farms were visited in each farm settlement or location but the samples were not separated in each farm owing to the number of cases or asymptomatic animals sampled at random in some of the farms based on the number of animals the farm owners allowed to be recruited, the cooperation obtained from the pig handlers and those that were qualified for enlisting that met the criteria for sampling according to the study design. Random sample collection from asymptomatic pigs was carried out to detect subclinical circulation of influenza virus including weaned and growers of naive population and adult pigs, hence all the samples were categorised based on the sampling location of Ojo or Ikorodu.

\subsection{Ethical Approval}

All guidelines of ethics involving animal experimentation in research were followed to standard. Ethical approval was sought and obtained from the Research, Ethics, Experimentation and Grant Review Committee of the College of Medicine University of Lagos, Idi-Araba and Lagos State Ministry of Health, Alausa, Ikeja.

\subsection{Sample Population, Collection, and Storage}

A total of 194 nasal samples were collected from both sick and healthy animals, including both sexes of different age groups ranging from piglets, nursery/weaner, fattening and adult pigs. Samples from sick pigs were collected as cases were reported. They were classified as those having influenza-like illness according to the World Organisation for Animal Health definition. Random sample collection from asymptomatic pigs of naive population were included to detect subclinical circulation of influenza. All samples were collected between October, 2015 and April, 2016. None of the study subjects had prior vaccination. Samples were collected according to World Organisation for Animal Health, OFFLU/OIE standard and protocol for collection of specimens for the detection of influenza virus in pigs. In brief, the pigs were restrained by guiding and holding them down with the head raised before gently inserting sterile swab into the nasal cavity in a dorsal-medial pattern. Surfaces of nasal mucosa of the 
two nares were gently swabbed within few seconds using circular motion to cover the parts for nasal mucosal secretions and surface epithelium sample. In order to ensure optimal sample collection, Dracon swabs (Copan Flock Tech. Srl, Italy) were used. They were inserted approximately to the depth of $1 \mathrm{~cm}$ in piglets $(<1$ month old), $2 \mathrm{~cm}$ in nursery pigs (1 $\square 2$ months old), $3-4 \mathrm{~cm}$ in fattening pigs (older than 2 months of age). Each swab was transferred into separate sterile cryovial containing $2 \mathrm{mls}$ aliquot of Dulbecco's Modified Eagle Medium viral transport medium with antibiotic (penicillin-streptomycin) and antifungal (amphotericin B) agents to prevent desiccation, death, bacterial and fungal growth. Dracon swabs handles were broken and removed by bending the handles backward and forward over the edge of the cryovial. Samples were kept on ice in coolers before they were transported to the laboratory for further processing. In the laboratory, samples were kept at $4^{\circ} \mathrm{C}$ for extraction the next day $(<24 \mathrm{hrs})$. All the samples were arranged, deactivated in a glove box, vigorously mix by vortexing within the transfer medium completely to dislodge the virus from the Dracon swabs and processed under a biological safety cabinet (BSC) class II.

\subsection{Laboratory Analysis}

Viral nucleic acids were extracted using commercially available extraction kit (Jena Bioscience, Germany) with modifications by adding $100 \mathrm{mg}$ molecular grade diatomaceous earth (SigmaAldrich, USA) in order to trap and bind the RNA. Extracts were investigated for the presence of influenza matrix gene by direct detection using conventional reverse transcription polymerase chain reaction (RT-PCR). DNA synthesis was carried out by invitro reverse-transcription of viral RNA primed by formulated amplification mixture One-Step RT-PCR kit (AgPath-ID ${ }^{\mathrm{TM}}$, Applied Biosystems by Life Technologies, Carlsbad, California) with DNA Taq polymerase and specific oligonucleotide primers FLUA (F) 5' AAG ACC AAT CCT GTC ACCTCT GA 3' and FLUA (R) 5' CAA AGC GTC TAC GCTGCA GTC C 3' targeting 104-base pair (Ward et al., 2004) which were incubated at $50{ }^{\circ} \mathrm{C}$ for $30 \mathrm{~min} ; 95^{\circ} \mathrm{C}$ for 5 minutes, $\left(95^{\circ} \mathrm{C}\right.$ for $30 \mathrm{secs}, 48-55$ ${ }^{\circ} \mathrm{C}$ for 30 secs, $72{ }^{\circ} \mathrm{C}$ for 30 secs $) \times 35-45$ cycles, $72{ }^{\circ} \mathrm{C}$ for 5 minutes in Applied Biosystems 9700 Gene Amp PCR System (Singapore). Amplicons were detected by 2\% agarose gel electrophoresis at 130 volts for 35 minutes (figure 1).

\subsection{Statistical Analyses}

Statistical analyses were done using Graph pad software 5.0, San Diego, USA to calculate the P-values with Chi-square and Fisher's exact tests. The level of significance was tested at $95 \%$ confidence interval

\subsection{Results And Discussion}

Out of the 194 samples analysed in this study, 25 (12.9\%) of them were positive for influenza A virus. Sample distributions and their test results with respect to different epidemiological parameters including: sampled locations and methods, sex, and period are as shown in table 1. Ojo farm was sampled twice, in October and April and hence accounted for higher proportion of the sample total, $120(61.9 \%)$ and higher number of positives, 20 (16.7\%) as against $5(6.8 \%)$ positives and 69 (93.2\%) negative results from Ikorodu farm. Statistical analysis was significant between the two locations $(\mathrm{P}, 0.03<0.05)$. The percentage proportion, $27.3 \%$ of the only six (6) positive results out of the 22 $(11.3 \%)$ samples analysed as reported cases was higher than that of $11 \%$ for nineteen (19) positive samples out of $172(88.7 \%)$ samples collected at random. P-value (0.04) was significant between the sick animals and healthy group in the sampled population. A large number of the population was sow with a total of $149(76.8 \%)$ that accounted for $21(14.1 \%)$ and 128 $(85.9 \%)$ positive and negative results respectively. Only $4(8.9 \%)$ boars were positive out of $45(23.2 \%)$ of them in the total population (Table 1). The p-value, 0.3 was significant between the sexes. There was no statistical difference between the sampled periods, October and April, p-value, 0.7. Close percentage values of $13.2 \%$ and $12 \%$ were obtained for the positive results of 20 out of $144(74.2 \%)$ and 6 out of $50(25.8 \%)$ samples collected in the months of October and April respectively (Table 1).

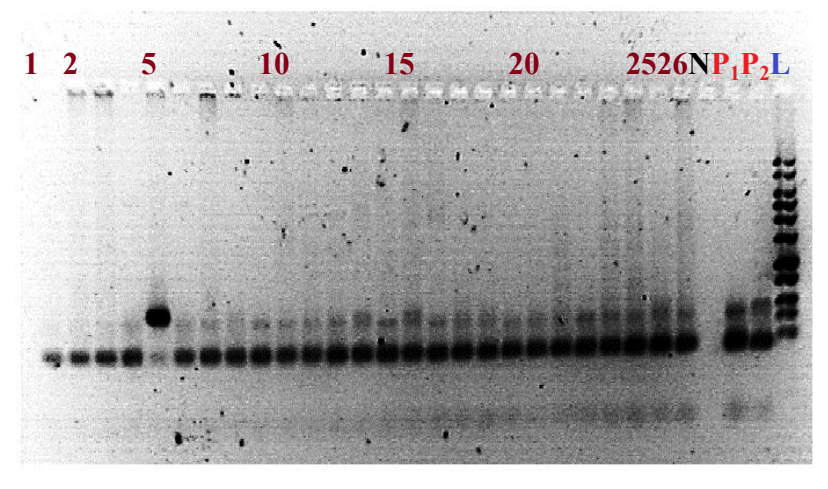

Lane 1- Negative, Lanes 2 to 26- Positive samples, N- Negative control, $\mathrm{P}_{1}$ and $\mathrm{P}_{2}$ - Positive controls, L- Ladder of 50 base pair (bp).

Fig. 1: Agarose gel image showing RT-PCR amplicons' bands to Influenza A virus matrix-gene. The target band size is $104 \mathrm{bp}$

Prevalence in percentage among the different category of animals with respect to their ages either as piglets, nursery/ weaners, fattening or adults was estimated and determined (figure 2). They were also compared with the entire population. The adult had $100 \%$ prevalence rate of detection compared to the nursery that were all negative.

Out of the 21 positive sows, 18 of them were fattening pigs while the others included 2 piglets and 1 adult. All the 4 positive boar pigs tested in this study were all fattening pigs. All the Six (6) reported animals (cases) were fattening pigs. Out of the 19 randomised samples that were positive, 16 of them were fattening pigs, 2 were piglets while the other 1 was an adult pig. Out of the 20 positive samples from Ojo, 17 were fattening pigs while others were 2 piglets and only 1 adult. Also, the only 5 positive samples from Ikorodu farm were all fattening pigs.

The frequency of clinical symptoms, disease burden and observable conditions among the subjects considered for this study were analysed (table 2). The clinical symptoms apart from the ILI were quite different from the conventional signs and symptoms pathognomonic of influenza virus in pigs. Emaciation 
and stunted growth were noticed in 4 animals and $75 \%$ of these animals were positive for IAV. Twenty five (25\%) of the animals with neurological disorder were positive while $66.7 \%$ of pregnant animals were also detected to be positive for IAV. The 2 reported dead animals were negative for IAV. Other clinical pictures observed included lack of appetite, weakness, constipation, swollen eye and bloody stool.

Influenza A viruses (IAVs) are one of the greatest threats of global pandemics due to their several hosts with occasional spill over to man. The incessant spread of influenza virus in swine increases the possibility of yielding more novel reassortants that can easily be transmitted among humans (Liu et al., 2012). Lack of seasonality of infection by swine influenza A virus and the ability of pigs to dock co-circulating influenza A virus from several hosts shows the need for continuous surveillance and timely detection of current circulating IAV in pigs (Decorte et al 2015). This is in line with the detection carried out in this study and justifies our aim to detect influenza A virus in pigs in Lagos, Nigeria.

The prevalence of $20(16.7 \%)$ influenza A virus detected in pigs in Ojo is lower compared to the prevalence rate of $31(26.7 \%)$ earlier detected in the same farm location but from different pig population in 2012 by (Anjorin et al, 2012). This current study hereby re-affirmed the presence of circulating influenza A virus in pigs in Lagos that was first reported in this part of the country in 2012. Lagos is the commercial nerve center of Africa and the most populated black city in the world with over 21 million people (Bakare, 2016) where pig husbandry is practiced both in backyard and commercial farming with low biosecurity and serious health risks.

Our study has also fulfilled the practice and philosophy of continuous surveillance of influenza virus in pigs in our environment with a view to alert the policy makers and report current circulating influenza virus especially the type A early enough for monitoring. However, the prevalence of $5(6.8 \%)$ positives detected in pigs tested in Ikorodu in this study is low compared to previous report in the same location.

The large Sow total population proportion of $149(76.8 \%)$ sampled in this study out of total animal population of 194 $(100 \%)$ tend to be a common population ratio in pig farm practice. The sampled farms had higher proportion of their animals to be sows and a few number as boars. This may be attributed to the intent of procreation from the sows that often give births to more piglets. This also justifies the high positivity detection rate of $14.1 \%$ in the sows compared to $8.9 \%$ of the boars. Also, different factors including hormonal changes, pregnancy and nursing practices lowers the immunity of the sows which may contribute to their susceptibility to influenza viral infection and sickness leading to viral presence and shedding.

The assertion of more sows coming down with influenza virus was statistical tested to be significant in this study with a p-value of 0.3. The samples collected in October and April was statistically insignificant. This is not surprising because studies have shown that influenza virus spreads all year round in pigs (CDC, 2016). Also, both April and October happened to be rainy season in the study locations with barely any meaningful weather differences.

Table 1: Epidemiological factors showing percentage distribution of samples in the total population; C-case samples, R-random samples

\begin{tabular}{|c|c|c|c|}
\hline PARAMETERS & TOTAL SAMPLE (\%) & $\begin{array}{c}\text { NO. OF POSITIVES } \\
\text { (\%) }\end{array}$ & $\begin{array}{c}\text { CHI-SQUARE } \\
\text { P-VALUES }\end{array}$ \\
\hline Local Govt. & & $20(16.7)$ & 0.03 \\
\hline Ojo & $120(61.9)$ & $5(6.8)$ & \\
\hline Ikorodu & $74(38.1)$ & & \\
\hline Sample type & & & 0.04 \\
\hline Reported cases & $22(11.3)$ & $19(11.0)$ & \\
\hline Randomised & $172(88.7)$ & & \\
\hline Sex & & & \\
\hline Boar & $45(23.2)$ & & 0.3 \\
\hline Sow & $149(76.8)$ & & \\
\hline Season & & & \\
\hline October & & & \\
\hline April & $50(25.8)$ & & \\
\hline
\end{tabular}

The prevalence rate of $100 \%$ detection in the adult pig cannot be said to be generalised since only 1 adult pig was involved. Over $90 \%$ of the positive samples were from piglets and fattened pigs. This agrees with the work of (Meseko et al., 2014) that reported 
over $78 \%$ positivity in young and growing pigs and adduced the higher proportionality in these pigs category to susceptibility due to population naivety. All the 41 nursery/weaned pigs examined in this study were negative (figure 2). This could be due to cross protective antibodies from maternal immunity against influenza virus.

Influenza virus has been described to cause grave effects in pigs, especially as a result of increased interval required to reach slaughter weight (Fouchier et al., 2003). Seventy five (75) \% emaciation and stunted growth were observed in 4 animals that were positive for influenza virus along with other clinical symptoms presented (Table 2). Some of the signs and symptoms observed in the study group apart from ILI were quite different from the conventional signs and symptoms pathognomonic of influenza virus in pigs including neurological disorder and death. Mortality in $2(11.1 \%)$ of the cases with outlined clinical manifestations was recorded but the samples from the 2 animals tested negative for influenza virus. This is the same with the number of recorded deaths reported in 2014 in Lagos pigs but with $<1 \%$ positive result in the considered population (Meseko et al., 2014). However, studies have shown that though influenza virus causes high morbidity in pigs but with low mortality (Brown, 2000).

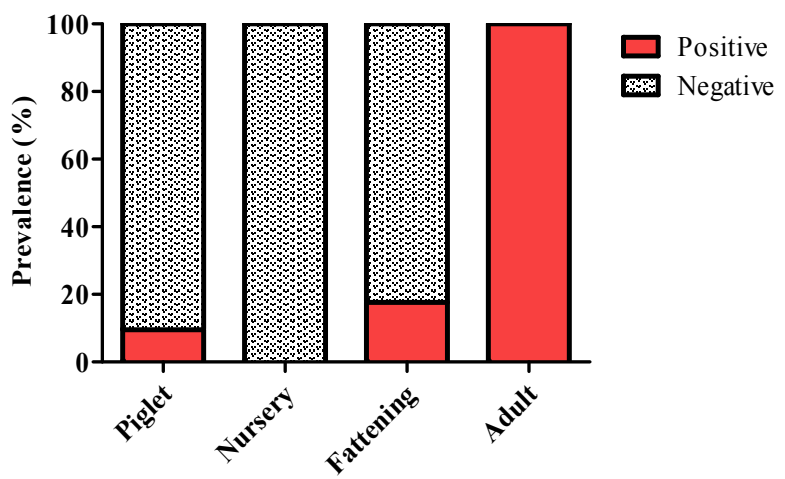

Fig. 2: Prevalence (\%) distribution among the different Pig categories

This study detected a prevalence rate of $12.9 \%$ as against the rare detection by PCR of influenza $A$ in swabs of African pigs reported by (Snoeck et al., 2015) with 0/264 in 2009 and 0/340 in 2012 from Nigeria, 0/62 in 2008-2010 from Benin, 0/1548 in 2009-2010 from Co^te d'Ivoire and 2/104 in 2009-2010 from Cameroon (Couacy-Hymann et al., 2012; Njabo et al., 2012) in West Africa sub-region where this research was carried out. There is also a wide margin between the finding in this study and that reported elsewhere in China with $1.69 \%$ prevalence in 11 out of 650 samples examined (Yu et al., 2009) and in Taiwan with $0.79 \%$ prevalence in 7 out of 881 samples tested for nucleoprotein gene by real time RT-PCR (Shieh et al., 2008). The result of our study is however slightly lower than the finding of (Meseko et al., 2014) that detected prevalence rate of $13.7 \%$ in 31 pigs out of 227 sick animals tested for IV matrix gene by RT-PCR in Lagos. This is expected as all the samples from our study were not collected from sick animals and sick animals are known to shed influenza virus in their nasal with peak in titer at 48 hours post infection and little or no viral shedding after 6-8 days (Kothalawala et al., 2006). This theory holds water and explains the higher percentage, $27.3 \%$ obtained from 6 positive samples out of the only 22 sick cases of pigs reported in the total population as against the higher number of randomized sampled population of 172 , out of which only $19(11 \%)$ were positive. On the other hand, the $19(11 \%)$ positive results obtained from the healthy/asymptomatic pigs has shown subclinical circulation of influenza virus in pigs in Lagos. P-value (0.04) was also significant between the sick animals and healthy group in the sampled population.

Our finding is however suggestive as part of its limitations that future studies should target more sick animals in different divisions of the State. Also, research funding is advocated so that molecular isolates can be further characterised by subtyping and genomic sequencing.

Table 2: Frequency of Clinical Symptoms and Disease burden in Positive Samples

$\begin{array}{cc}\text { CLINICAL SIGNS } & \text { FREQUENCY (\% POSITIVES) } \\ \text { Lean/ Stunted growth } & 3(75) \\ \text { Lack of appetite } & 1(0) \\ \text { Weakness } & 1(0) \\ \text { Constipation } & 1(0) \\ \text { Swollen eye } & 1(0) \\ \text { Neurological disorder } & 4(25) \\ \text { Bloody stool } & 1(0) \\ \text { Death } & 2(0) \\ \text { Pregnancy condition } & 3(66.7)\end{array}$

\subsection{Conclusion}

This study determined influenza viral burden in pigs with a molecular prevalence of $12.9 \%$ to influenza A. It further established the sub-clinical circulation and re-affirmed the clinical detection of influenza virus in both healthy and sick pig populations respectively in Lagos, Nigeria. Therefore, the detection of IAV in commercial pigs in Nigeria accentuates the importance of continuous surveillance of the virus so as to prevent the advent of virulent strains that may be transmitted to Pig-handlers and the community at large.

\subsection{Acknowledgements}

We are grateful to the owners of the farms sampled for this study, the Director, Avian Influenza Control Project (AICP) under the Federal Ministry of Health, Virology Research Laboratory, CMUL/LUTH, Idi-Araba, Lagos, and the Management of the Lagos State Ministry of Health, Alausa, Ikeja, Lagos for their supports. The abstract for this study was presented at the fifth Scientific Conference of the Faculty of Basic Medical Sciences under no.: FBMS/5SC/AB/029 at the College of Medicine of the

University of Lagos, Idi-Araba, Nigeria in June 1st -2nd, 2016. 


\subsection{Conflict Of Interest}

All Authors have declared that there are no conflicts of interest.

\section{Authors' Contributions}

Conception: AAA, OSA

Design: AAA, OSA, OWA

Execution: AAA, JAB, OBO, OMR, ARA, AMA

Interpretation: AAA, SOB, OSA, JAB, OAOB, OBO

Writing the manuscript: AAA, SOB, OAOB, OSA

\section{References}

Anjorin, A., Omilabu, S., Salu, O., Oke, B., 2012. Detection of Influenza A Virus in Pigs in Lagos, Nigeria. African Journal of Clinical and Experimental Microbiology 13, 41-45.

Bakare, B. 2016. Lagos State Government. In Gains of Ambode's all inclusive governance, LASG, ed. (Ikeja, Lagos State Government).

Brown, I.H., 2000. The epidemiology and evolution of influenza viruses in pigs. Vet Microbiol 74, 29-46.

CDC, 2012. Updates: influenza A (H3N2)v transmission and guidelinefive states. Morbidity and Mortality Weekly Report 60, 1741-1744.

CDC 2014. Key Facts about Swine Influenza (Swine Flu) in Pigs (Atlanta, Georgia, CDC).

CDC 2015. Influenza Epidemiology (Atlanta, Georgia, CDC).

CDC 2016. Key Facts about Swine Influenza (Swine Flu) in Pigs (Atlanta, Georgia, CDC).

Couacy-Hymann, E., Kouakou, V.A., Aplogan, G.L., Awoume, F., Kouakou, C.K., Kakpo, L., Sharp, B.R., McClenaghan, L., McKenzie, P., Webster, R.G., Webby, R.J., Ducatez, M.F., 2012. Surveillance for influenza viruses in poultry and swine, west Africa, 2006-2008. Emerg Infect Dis 18, 1446-1452.

Decorte, I., Steensels, M., Lambrecht, B., Cay, A.B., De Regge, N., 2015. Detection and Isolation of Swine Influenza A Virus in Spiked Oral Fluid and Samples from Individually Housed, Experimentally Infected Pigs: Potential Role of Porcine Oral Fluid in Active Influenza A Virus Surveillance in Swine. PloS one 10, e0139586.

Dee, S. 2014. Swine Influenza. In The Merck veterinary manual. http://www.oie.int/fileadmin/Home/eng/Animal_Health_in_the_Worl d/docs/pdf/Disease_cards/SWINE_INFLUENZA.pdf

Fouchier, R.A., Osterhaus, A.D., Brown, I.H., 2003. Animal influenza virus surveillance. Vaccine 21, 1754-1757.

Garten, R.J., Davis, C.T., Russell, C.A., Shu, B., Lindstrom, S., Balish, A., Sessions, W.M., Xu, X., Skepner, E., Deyde, V., OkomoAdhiambo, M., Gubareva, L., Barnes, J., Smith, C.B., Emery, S.L., Hillman, M.J., Rivailler, P., Smagala, J., de Graaf, M., Burke, D.F., Fouchier, R.A., Pappas, C., Alpuche-Aranda, C.M., Lopez-Gatell, H., Olivera, H., Lopez, I., Myers, C.A., Faix, D., Blair, P.J., Yu, C., Keene, K.M., Dotson, P.D., Jr., Boxrud, D., Sambol, A.R., Abid, S.H., St George, K., Bannerman, T., Moore, A.L., Stringer, D.J., Blevins, P., Demmler-Harrison, G.J., Ginsberg, M., Kriner, P., Waterman, S., Smole, S., Guevara, H.F., Belongia, E.A., Clark, P.A., Beatrice, S.T., Donis, R., Katz, J., Finelli, L., Bridges, C.B., Shaw,
M., Jernigan, D.B., Uyeki, T.M., Smith, D.J., Klimov, A.I., Cox, N.J., 2009. Antigenic and genetic characteristics of swine-origin 2009 $\mathrm{A}(\mathrm{H} 1 \mathrm{~N} 1)$ influenza viruses circulating in humans. Science 325, 197201.

Imai, M., Kawaoka, Y., 2012. The role of receptor binding specificity in interspecies transmission of influenza viruses. Current Opinion in Virology 2, 160-167.

Imai, M., Watanabe, T., Hatta, M., Das, S.C., Ozawa, M., Shinya, K., Zhong, G., Hanson, A., Katsura, H., Watanabe, S., Li, C., Kawakami, E., Yamada, S., Kiso, M., Suzuki, Y., Maher, E.A., Neumann, G., Kawaoka, Y., 2012. Experimental adaptation of an influenza H5 HA confers respiratory droplet transmission to a reassortant $\mathrm{H} 5$ HA/H1N1 virus in ferrets. Nature 486, 420-428.

Kothalawala, H., Toussaint, M., Gruys, E., 2006. An overview of swine influenza. Veterinary quarterly $28,45-53$.

Lindstrom, S., Garten, R., Balish, A., Shu, B., Emery, S., Berman, L., Barnes, N., Sleeman, K., Gubareva, L., Villanueva, J., Klimov, A., 2012. Human infections with novel reassortant influenza A(H3N2)v viruses, United States, 2011. Emerg Infect Dis 18, 834-837.

Liu, Q., Ma, J., Liu, H., Qi, W., Anderson, J., Henry, S.C., Hesse, R.A., Richt, J.A., Ma, W., 2012. Emergence of novel reassortant H3N2 swine influenza viruses with the 2009 pandemic H1N1 genes in the United States. Archives of virology 157, 555-562.

Meseko, C., Odaibo, G., Olaleye, D., 2014. Detection and isolation of 2009 pandemic influenza A/H1N1 virus in commercial piggery, Lagos Nigeria. Veterinary microbiology 168, 197-201.

Myers, K.P., Olsen, C.W., Gray, G.C., 2007. Cases of Swine Influenza in Humans: A Review of the Literature. Clinical infectious diseases : an official publication of the Infectious Diseases Society of America 44, 1084-1088.

Njabo, K.Y., Fuller, T.L., Chasar, A., Pollinger, J.P., Cattoli, G., Terregino, C., Monne, I., Reynes, J.M., Njouom, R., Smith, T.B., 2012. Pandemic A/H1N1/2009 influenza virus in Swine, Cameroon, 2010. Vet Microbiol 156, 189-192.

Rogers, G.N., Paulson, J.C., 1983. Receptor determinants of human and animal influenza virus isolates: differences in receptor specificity of the H3 hemagglutinin based on species of origin. Virology 127, 361373.

Sharma, N., Kumar, M., Sharma, B., Goel, R., Ghosh, S., Pandey, M., \& Sharma, S, 2013. H1N1 and molecular diagnosis-rapid and ease in viral and disease monitoring. Journal of Biomedical and Pharmaceutical Research 2, 135-142.

Shieh, H.-K., Chang, P.-C., Chen, T.-H., Li, K.-P., Chan, C.-H., 2008. Surveillance of avian and swine influenza in the swine population in Taiwan, 2004. J Microbiol Immunol Infect 41, 231-242.

Smith, G.J., Vijaykrishna, D., Bahl, J., Lycett, S.J., Worobey, M., Pybus, O.G., Ma, S.K., Cheung, C.L., Raghwani, J., Bhatt, S., Peiris, J.S., Guan, Y., Rambaut, A., 2009. Origins and evolutionary genomics of the 2009 swine-origin H1N1 influenza A epidemic. Nature 459, $1122-1125$. 
Snoeck, C.J., Abiola, O.J., Sausy, A., Okwen, M.P., Olubayo, A.G., Owoade, A.A., Muller, C.P., 2015. Serological evidence of pandemic (H1N1) 2009 virus in pigs, West and Central Africa. Veterinary microbiology 176, 165-171.

Torremorell, M., Allerson, M., Corzo, C., Diaz, A., Gramer, M., 2012. Transmission of Influenza A Virus in Pigs. Transboundary and Emerging Diseases 59, 68-84.

Ward, C.L., Dempsey, M.H., Ring, C.J., Kempson, R.E., Zhang, L., Gor, D., Snowden, B.W., Tisdale, M., 2004. Design and performance testing of quantitative real time PCR assays for influenza A and B viral load measurement. J Clin Virol 29, 179-188.

Yu, H., Zhang, P.-C., Zhou, Y.-J., Li, G.-X., Pan, J., Yan, L.-P., Shi, X.X., Liu, H.-L., Tong, G.-Z., 2009. Isolation and genetic characterization of avian-like $\mathrm{H} 1 \mathrm{~N} 1$ and novel ressortant $\mathrm{H} 1 \mathrm{~N} 2$ influenza viruses from pigs in China. Biochemical and biophysical research communications $386,278-283$. 